\title{
Melatonin as an Anti-angiogenetic, Immunomodulatory and Antitumoral Agent
}

\author{
Kubilay Dogan Kilic ${ }^{1}$, Yigit Uyanikgil ${ }^{1,2}$, Emel Oyku Cetin ${ }^{3}$ and Mehmet Turgut ${ }^{4^{*}}$ \\ ${ }^{1}$ Department of Histology and Embryology, Ege University, School of Medicine, Izmir, Turkey \\ ${ }^{2}$ Cord Blood, Cell-tissue Research and Application Center, Ege University, Izmir, Turkey \\ ${ }^{3}$ Department of Biopharmaceutics and Pharmacokinetics, Ege University, Izmir, Turkey \\ ${ }^{4}$ Department of Neurosurgery, Adnan Menderes University School of Medicine, Aydin, Turkey
}

"Corresponding author: Mehmet Turgut, Associate Professor of Neurosurgery, Department of Neurosurgery, Adnan Menderes University School of Medicine, 09100 Aydın, Turkey, 1410 Laney Walker Blvd, CN3124A, Augusta, GA 30912, USA, Tel: +90 256 2134874; Fax: +90 2562120146 ; E-mail: drmturgut@yahoo.com

Rec date: June 08, 2016; Acc date: June 09, 2016; Pub date: June 15, 2016

Copyright: (c) 2016 Kilic KD, et al. This is an open-access article distributed under the terms of the Creative Commons Attribution License, which permits unrestricted use, distribution, and reproduction in any medium, provided the original author and source are credited.

\section{Melatonin}

Today, it is well-known that melatonin (N-acetyl-5methoxytryptamine) which is a hormone secreted from pineal gland has oncostatic properties, specifically on hormone-dependent ones. Due to the variation of wide impact of melatonin mechanism, it has diverse courting with antitumor. In fact, this effect is a result of its antiangiogenetic effects [1]. Furthermore, antitumor activity of the melatonin may be explained its immunomodulatory, anti-proliferative and anti-oxidant effects. Vascular Endothelial Growth Factor (VEGF) is the most angiogenisc element and related to the diagnosis of most cancers. There are capable studies that investigated the impact of melatonin on angiogenesis; Lissoni et al. have evaluated the effects of melatonin remedy on VEGF blood ranges in advanced stage patients via displaying that it has function as a natural anti-angiogenic molecule with angiogenesis-dependent cancers proliferation [2]. Afterwards, Mias et al. applied ex vivo pre-treatment with melatonin to enhance survival, paracrine activity, and efficiency of Mesenchymal Stem Cells (MSCs). Their acute renal failure survival rate of rats strongly expanded after MSC pre-treatment. This effect came with over stimulation of angiogenesis and proliferation of renal cells [3].

Angiogenesis is associated with tumor development, an important process. As long as tumors enlarge, diffusion distances from the prevailing vascular deliver increases and it reasons hypoxia for most cancers cells. Tumor proliferation and migration calls for vascularisation to feed and guide tumor cells with additives. The key regulator of hypoxia triggered angiogenesis is hypoxia inducible factor (HIF)-1. HIF-1 alpha is stabilized with the aid of hypoxia triggered reactive oxygen species (ROS) and uprises the expression of hypoxic genes, consisting of VEGF. In their study Park et al. observed that melatonin destabilizes hypoxia-prompted HIF-1 alpha protein tiers in colon for most cancer cells [4]. This destabilization of HIF-1 alpha resulted from the antioxidant activity of melatonin against ROS brought on by means of hypoxia [4]. Those findings advocate that melatonin may play a lead position in tumor suppression through HIF-1-mediated angiogenesis inhibition [4].

In order to support the relation between melatonin and VEGF, the study of Dai et al. is important [5]. They stated that physiologic concentrations of melatonin don't have any apparent impact on the VEGF expression, however, pharmacologic concentrations of melatonin suppress the VEGF mRNA and protein degrees brought about by hypoxia echoer cobalt chloride $(\mathrm{CoCl} 2)$ [5]. Melatonin also decreases HIF-1 alpha protein levels. Their data display that melatonin in excessive concentration markedly reduces the expression of endogenous VEGF and HIF-1 alpha-induced via $\mathrm{CoCl} 2$ in different types of cultured cancers cells [5].

Gathering information together indicates that oxidative stress performs a fundamental function in regulating the activity of Matrix Metalloproteinases (MMPs) which might be involved in several cellular processes include angiogenesis [6]. Melatonin induces apoptosis in liver cancer and suggests anti-angiogenic effect in numerous tumors. Carbajo-Pescador et al. used human HepG2 liver cancer cells as an in vitro model to investigate the anti-angiogenic consequences of melatonin [7]. They suggested that melatonin exerts an anti-angiogenic activity in HepG2 cells by interfering the transcriptional activation of VEGF, thru HIF1 alpha and STAT3 [7]. Results offer evidence to recollect this indole as a strength antiangiogenic agent for hepatocellullar carcinoma treatment [7].

In conclusion, melatonin in high concentration can markedly reduce the Human Umbilical Vein Endothelial Cells (HUVEC) proliferation and induce cellular apoptosis Moreover can decrease the cell cycle length by modulating $\mathrm{p} 53$ and $\mathrm{Bax} / \mathrm{Bcl}-2$ expression. Treatment with melatonin may be an innovative and challenging therapy for cancer anti-angiogenesis therapeutics. In the future, most cancers therapy protocols embedded with low concentrations of melatonin can put a light for further investigations for anti-angiogenic process. Melatonin in high concentration can markedly reduce the HUVEC proliferation while setting off apoptosis with modulating p53 and $\mathrm{Bax} / \mathrm{Bcl}-2$ expression during cell cycle. Now, we strongly believe that treatment with melatonin may be a revolutionary and tough remedy for anti-angiogenic cancer therapy [8]. The wound healing is an angiogenesis-dependent process. Post wounding HO-2 protein levels barely increase in both the control and melatonin treatment group. In a study, melatonin treatment group shows that a further increase (although not significant) in $\mathrm{HO}-2$ protein levels and supported healing through angiogenesis [9]. Melatonin induces the production of interleukin-1, Tumor Necrosis Factor (TNF)- $\alpha$ and Transforming Growth Factor (TGF) cytokines. Additionally it is an immunomodulator and a neuroendocrine hormone which stimulates monocyte cytokine and fibroblast proliferation in angiogenic process. Recent studies have determined that melatonin can also have a positive effect on both angiogenesis and wound healing [10]. In a recent study, melatonin increased angiogenesis which has relation with the refinement of MMP-2 expression and activity and also upregulation of VEGF in rat cornea. Melatonin shielded from gastric lesions by upraising angiogenesis thru upregulation of VEGF accompanied with the support of over-expression of MMP-2. It showed that melatonin exerts angiogenesis thru MMP-2 and VEGF over-expression all through safety and recuperation of gastric ulcers [11]. 
Citation: Kilic KD, Uyanikgil Y, Cetin EO, Turgut M (2016) Melatonin as an Anti-angiogenetic, Immunomodulatory and Antitumoral Agent. J Brain Tumors Neurooncol 1: e102.

Page 2 of 2

\section{References}

1. Mediavilla MD, Sanchez-Barcelo EJ, Tan DX, Manchester L, Reiter R, (2010) Basic mechanisms involved in the anti-cancer effects of melatonin. Curr Med Chem 17: 4462-4481.

2. Lissoni P, Rovelli F, Malugani F, Bucovec R, Conti A, et al. (2001) Antiangiogenic activity of melatonin in advanced cancer patients. Neuro Endocrinol Lett 22: 45-47.

3. Mias C, Trouche E, Seguelas MH, Calcagno F, Dignat-George F, et al. (2008) Ex vivo pretreatment with melatonin improves survival, proangiogenic/mitogenic activity, and efficiency of mesenchymal stem cells injected into ischemic kidney. Stem Cells 26: 1749-1757.

4. Park SY, Jang WJ, Yi EY, Jang JY, Jung Y, et al. (2010) Melatonin suppresses tumor angiogenesis by inhibiting HIF-1a stabilization under hypoxia. J Pineal Res 48: 178-184.

5. Dai M, Cui P, Yu M, Han J, Li H, et al. (2008) Melatonin modulates the expression of VEGF and HIF-1 alpha induced by $\mathrm{CoCl} 2$ in cultured cancer cells. J Pineal Res 44: 121-126.
6. Swarnakar S, Paul S, Singh LP, Reiter RJ (2011) Matrix metalloproteinases in health and disease: regulation by melatonin. J Pineal Res 50: 8-20.

7. Carbajo-Pescador S, Ordoñez R, Benet M, Jover R, García-Palomo A, et al (2013) Inhibition of VEGF expression through blockade of Hifla and STAT3 signalling mediates the anti-angiogenic effect of melatonin in HepG2 liver cancer cells. Br J Cancer 109: 83-91.

8. Cui P, Luo Z, Zhang H, Su Y, Li A, et al. (2006) Effect and mechanism of melatonin's action on the proliferation of human umbilical vein endothelial cells. J Pineal Res 41: 358-362.

9. Pugazhenthi K, Kapoor M, Clarkson AN, Hall I, Appleton I (2008) Melatonin accelerates the process of wound repair in full-thickness incisional wounds. J Pineal Res 44: 387-396.

10. Soybir G, Topuzlu C, Odabas O, Dolay K, Bilir A, et al. (2003) The effects of melatonin on angiogenesis and wound healing. Surg Today 33: 896-901.

11. Ganguly K, Sharma AV, Reiter RJ, Swarnakar S (2010) Melatonin promotes angiogenesis during protection and healing of indomethacin-induced gastric ulcer: role of matrix metaloproteinase-2. J Pineal Res 49: 130-140. 